\title{
Tolerability and safety of gastroretentive once-daily gabapentin tablets for the treatment of postherpetic neuralgia
}

This article was published in the following Dove Press journal:

Journal of Pain Research

22 June 2012

Number of times this article has been viewed

\section{Gordon A Irving' \\ Michael Sweeney ${ }^{2}$}

'Swedish Pain and Headache Center, Seattle, WA, USA; ${ }^{2}$ Depomed, Menlo Park, CA, USA
Correspondence: Gordon Irving Swedish Pain and Headache Center, I I0I Madison St, Suite 200, Seattle, WA 98104, USA

Tel +l 2062152537

Fax +l 2063862149

Email gordon.irving@swedish.org
Objective: An immediate-release formulation of gabapentin is approved for treatment of postherpetic neuralgia (PHN). This formulation, however, requires multiple daily dosing, usually three times per day, and is associated with a high incidence of somnolence and dizziness. We assessed the tolerability and safety of a once-daily gastroretentive formulation of gabapentin (G-GR) in phase 3 clinical trials in patients with PHN.

Research design and methods: Data were pooled from two placebo-controlled studies involving 723 patients (G-GR $1800 \mathrm{mg}, \mathrm{n}=359$; placebo, $\mathrm{n}=364$ ). Patients (43\% male, mean age 66 years) with PHN pain $>4$ ( $0-10$ scale) for $\geq 3$ months were enrolled. Summary statistics for the incidence of treatment-emergent adverse events (AEs) were performed. Laboratory parameters and vital signs were assessed.

Results: Treatment-emergent AEs were reported in $48 \%$ of patients (G-GR, 54\%; placebo, 42\%) and led to discontinuation in $8 \%$ of patients (G-GR, 10\%; placebo, 7\%). The most frequent ( $\geq 3 \%$ in any group) AEs were dizziness (G-GR, 11\%; placebo, 2\%), somnolence (G-GR, 5\%; placebo, 3\%), headache (G-GR, 4\%; placebo, 4\%), peripheral edema (G-GR, 4\%; placebo, $<1 \%$ ), and diarrhea (G-GR, 3\%; placebo, 3\%). Serious AEs were reported in seven patients in the G-GR group ( $2 \%$ ) and ten patients in the placebo group (3\%). There were two deaths, both in the placebo group. No serious AEs were considered related to treatment. Mean values for laboratory parameters and vital signs at the end of each study were similar between groups.

Conclusion: G-GR was safe and well tolerated for the treatment of PHN.

Keywords: gabapentin, postherpetic neuralgia, adverse events, dizziness, somnolence, gastroretentive

\section{Introduction}

Postherpetic neuralgia (PHN) is a neuropathic pain syndrome characterized by persistence of pain after healing of acute herpes zoster rash (shingles). It is often defined by the persistence of pain for at least 3 months, ${ }^{1}$ although the pain may resolve spontaneously in a considerable proportion of patients between 3 and 6 months. ${ }^{2}$ PHN pain usually presents as constant burning, aching, throbbing pain or intermittent sharp, shooting/ stabbing pain, and allodynia is reported by most patients. ${ }^{3}$ PHN has been estimated to occur in up to $20 \%$ of patients with herpes zoster, and the incidence of both herpes zoster and PHN as well as the severity of PHN pain increases with patient age. ${ }^{3}$

Immediate-release gabapentin (gabapentin TID) is approved by the US Food and Drug Administration for the treatment of PHN. However, that formulation has several limitations, including high incidences of dizziness $(28 \% \mathrm{vs} 8 \%$ for placebo) and somnolence ( $21 \%$ vs $5 \%$ for placebo). ${ }^{4}$ Furthermore, because absorption of gabapentin 
occurs via a saturable transport mechanism, the amount of gabapentin delivered by gabapentin TID may overwhelm the transporters located in the proximal small intestine. Thus, as the dosage is increased, the proportion of drug absorbed is decreased, ${ }^{5}$ and to maintain therapeutic levels, multiple daily doses are required.

A once-daily gastroretentive formulation of gabapentin (Gralise, referred to herein as G-GR) was recently approved for the treatment of PHN. The gastroretentive technology used in G-GR maintains the tablet in the fed stomach for up to 8 hours. While in the stomach, G-GR gradually releases gabapentin to its uptake transporters located in the proximal small intestine. ${ }^{6}$ This gradual release helps optimize absorption of gabapentin by the saturable transporters.

The first placebo-controlled, phase 3 study of gastroretentive gabapentin (1800 mg/day) compared G-GR and a divided-dose regimen with placebo in 400 patients who had a duration of $\mathrm{PHN} \geq 3$ months. The study ran for 10 weeks (including 2 weeks of dose titration), followed by 1 week of dose tapering. ${ }^{7}$ Although the study did not meet the primary efficacy end point (baseline observation carried forward [BOCF] least-squares mean change in average daily pain [ADP] score from baseline to week 10) due to an unexpectedly high placebo response, post hoc analysis demonstrated that the placebo response was especially evident in patients whose rash had healed $<6$ months prior to study entry. Furthermore, most secondary efficacy end points showed statistically significant improvement in the G-GR arm compared with placebo.

Given those promising results, a second 10-week, placebocontrolled, phase 3 study was conducted using $1800 \mathrm{mg}$ G-GR in patients whose duration of PHN was $\geq 6$ months $(n=452) .{ }^{8}$ In that study, the change in ADP intensity score (the primary end point) was -2.1 for once-daily gabapentin vs -1.6 for placebo ( $P=0.013, \mathrm{BOCF}$ analysis $)$. The between-group difference reached statistical significance at week 1 and remained significant throughout the study. Figure 1 shows the change in ADP intensity score over placebo for each of the two phase 3 studies with the pooled change in ADP intensity score data from the two studies.

In this pooled analysis, we examined the tolerability and safety of G-GR in patients with PHN from the two 11-week phase 3 clinical trials.

\section{Patients and methods}

This was an analysis of data pooled from two randomized, placebo-controlled studies of patients with PHN who had a pain intensity score of at least 4 on the Likert numerical rating scale $(0-10)$ and were treated with either G-GR $(1800 \mathrm{mg} /$ day) or placebo. The studies included in this analysis have been described in detail elsewhere (clinicaltrials.gov identifiers NCT00335933 and NCT00636636). ${ }^{7,8}$ Briefly, both studies recruited patients at least 18 years of age with neuropathic pain of either $\geq 3$ months ${ }^{7}$ or $\geq 6$ months $^{8}$ after the healing of a herpes zoster skin rash. One study was conducted entirely within the United States, ${ }^{7}$ whereas the other enrolled 259 patients from the United States, 161 patients from Russia, and 32 patients from Argentina. ${ }^{8}$ Patients being treated with drugs that could affect pain scores were required to undergo an initial washout period.

Exclusion criteria included: prior lack of response to treatment with gabapentin at doses of $\geq 1200 \mathrm{mg} /$ day or pregabalin at doses $\geq 300 \mathrm{mg} /$ day; dose-limiting adverse effects with gabapentin or hypersensitivity to gabapentin; neurolytic/neurosurgical treatment for PHN; severe pain unrelated to PHN; use of injected anesthetics or steroids within 30 days; immunocompromised state; creatinine clearance $(\mathrm{CrCl})<50 \mathrm{~mL} /$ minute; gastric reduction surgery;

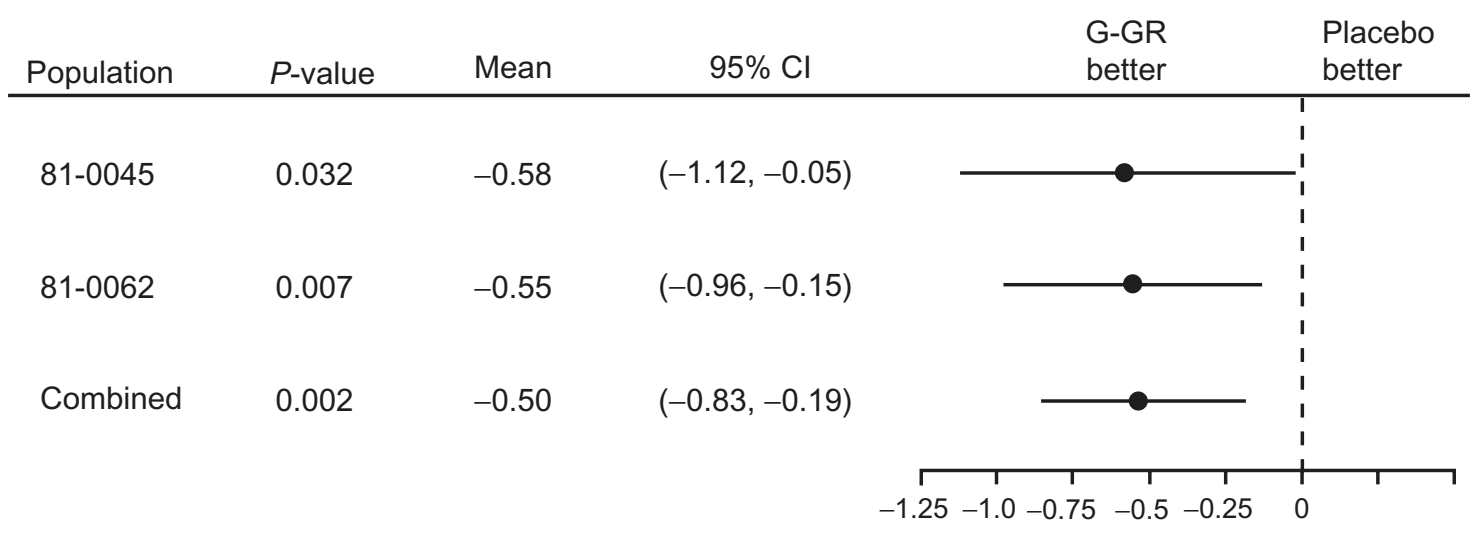

Figure I Forest plot of change in average daily pain score from baseline, placebo subtracted, last-observation-carried-forward methodology. Abbreviations: G-GR, once-daily gastroretentive gabapentin; $\mathrm{Cl}$, confidence interval. 
history of substance abuse within the previous year; or any skin condition that could modify sensation in the affected area. Patients underwent a 1 -week pretreatment period to establish baseline measurements, and those who continued to meet the pain score eligibility requirements were randomized to 10 weeks of treatment with G-GR $1800 \mathrm{mg}$ dosed once daily (titrated up over 2 weeks) or placebo followed by 1 -week of gabapentin dose tapering. One of the studies also included patients randomized to receive G-GR $1800 \mathrm{mg}$ as an asymmetric divided dose, ${ }^{7}$ but those data were not included in the current analysis.

Efficacy and safety data for each study have been reported previously. ${ }^{7,8}$ In this analysis, tolerability and safety data from both studies were pooled. The data included study medication compliance, the incidence of treatment-emergent adverse events (AEs), serious AEs (SAEs), study discontinuations, hematology, blood chemistry, and vital signs. All safety analyses were performed on the safety population consisting of all patients who received at least one dose of the study drug. AEs were coded using the Medical Dictionary for Regulatory Activities version 9.0. The number and percentage of patients reporting one or more AEs were categorized by AE preferred term and AE system organ class and summarized by treatment group. Summary statistics for the analyses of pooled study data were performed using SAS (Cary, NC) software (version 9.1.3 or higher).

\section{Results}

A total of 722 patients received at least one dose of study medication and were included in the safety population (G-GR, $n=359$; placebo, $n=364$ ). Baseline characteristics of the patients are shown in Table 1. Over half the patients were female, both groups were mostly Caucasian (88.5\%), and the mean age of patients was approximately 66 years. Overall compliance with study medication was slightly higher for patients in the G-GR group compared with placebo (mean compliance, 99.2\% vs 98.5\%). Reasons for study discontinuation are listed in Figure 2. Although there were more AEs in the G-GR group (194/359, 54.0\%) than in the placebo group $(154 / 364,42.3 \%)$, discontinuations were slightly lower overall for patients in the G-GR group compared with the placebo group (16.4\% vs 19.5.\%). AEs were the most common reason for discontinuation and were more common in the G-GR group than in the placebo group $(9.7 \%$ vs $6.0 \%)$. Lack of efficacy was a more common reason for discontinuation in the placebo group than in the G-GR group $(6.0 \%$ vs $2.5 \%)$. The most frequently occurring $\mathrm{AE}$ that led to discontinuation was dizziness (G-GR, 8/359, 2.2\%;
Table I Patient disposition and baseline characteristics of the safety population

\begin{tabular}{|c|c|c|c|}
\hline & $\begin{array}{l}\text { G-GR } \\
(n=359)\end{array}$ & $\begin{array}{l}\text { Placebo } \\
(n=364)\end{array}$ & $\begin{array}{l}\text { Total } \\
(n=723)\end{array}$ \\
\hline \multicolumn{4}{|l|}{ Age, years } \\
\hline Mean (SD) & $66.3(12.9)$ & $65.9(11.8)$ & $66.1(12.4)$ \\
\hline Range & $25-89$ & $21-87$ & $21-89$ \\
\hline \multicolumn{4}{|l|}{ Sex, n (\%) } \\
\hline Female & $213(59.3)$ & $202(55.5)$ & $415(57.4)$ \\
\hline Male & 146 (40.7) & $162(44.5)$ & $308(42.6)$ \\
\hline \multicolumn{4}{|l|}{ Race, n (\%) } \\
\hline Caucasian & $313(87.2)$ & $327(89.8)$ & $640(88.5)$ \\
\hline Black & $17(4.7)$ & $10(2.7)$ & $27(3.7)$ \\
\hline Hispanic & $22(6.1)$ & $22(6.0)$ & $44(6.1)$ \\
\hline Other & $7(1.9)$ & $5(1.4)$ & $12(1.7)$ \\
\hline \multicolumn{4}{|c|}{ ADP score, baseline } \\
\hline Mean (SD) & $6.5(1.4)$ & $6.6(1.4)$ & $6.5(1.4)$ \\
\hline Range & $4.0-10$ & $4.0-10$ & $4.0-10$ \\
\hline
\end{tabular}

Note: Includes patients initially randomized to receive asymmetric divided dose of G-GR in one study (asymmetric divided dose group not included in this analysis).

Abbreviations: ADP, average daily pain; G-GR, once-daily gastroretentive gabapentin; SD, standard deviation.

placebo, 2/364, 0.6\%); no other AE led to discontinuation in more than $1 \%$ of patients in the G-GR group. All incidences of these AEs except for two $(0.6 \%)$ in the G-GR group and one $(0.3 \%)$ in the placebo group were mild or moderate in severity. Almost all patients $(95.0 \%$ of G-GR patients and $93.4 \%$ of placebo patients) were able to achieve an $1800-\mathrm{mg}$ dose within 2 weeks. Only $3.6 \%$ of G-GR patients and $3.0 \%$ of placebo patients discontinued during the titration period due to an AE. SAEs were reported more frequently in the placebo group (G-GR, 1.9\%; placebo, 2.7\%). All except one SAE were considered unrelated to the study drug. An SAE of chronic pancreatitis in one patient (G-GR group) was deemed probably related to treatment, although the relationship to the study drug was challenged when the patient was seen by a local gastroenterologist. There were two deaths in the placebo group, both from myocardial infarction. Both patients were in their 70s and had a history of dyslipidemia. One patient had a history of hypertension, coronary bypass graft, and stenting. For the second patient, hypertension and hyperlipidemia were listed as secondary causes of death.

AEs were further stratified by age ( $<65$ years vs $\geq 65$ years) and sex (male vs female) to examine potential influences of these factors (Figure 3). Although the incidences of AEs within each treatment group, including dizziness and somnolence, were generally consistent regardless of patient age or sex, there were a few notable differences. For example, compared with the patients $\geq 65$ years, the younger patients ( $<65$ years) reported nausea more frequently ( $<65$ years: G-GR, 6.8\%; placebo, $1.4 \%$ vs $\geq 65$ years: G-GR, $1.3 \%$; placebo, $5.0 \%$ ). 


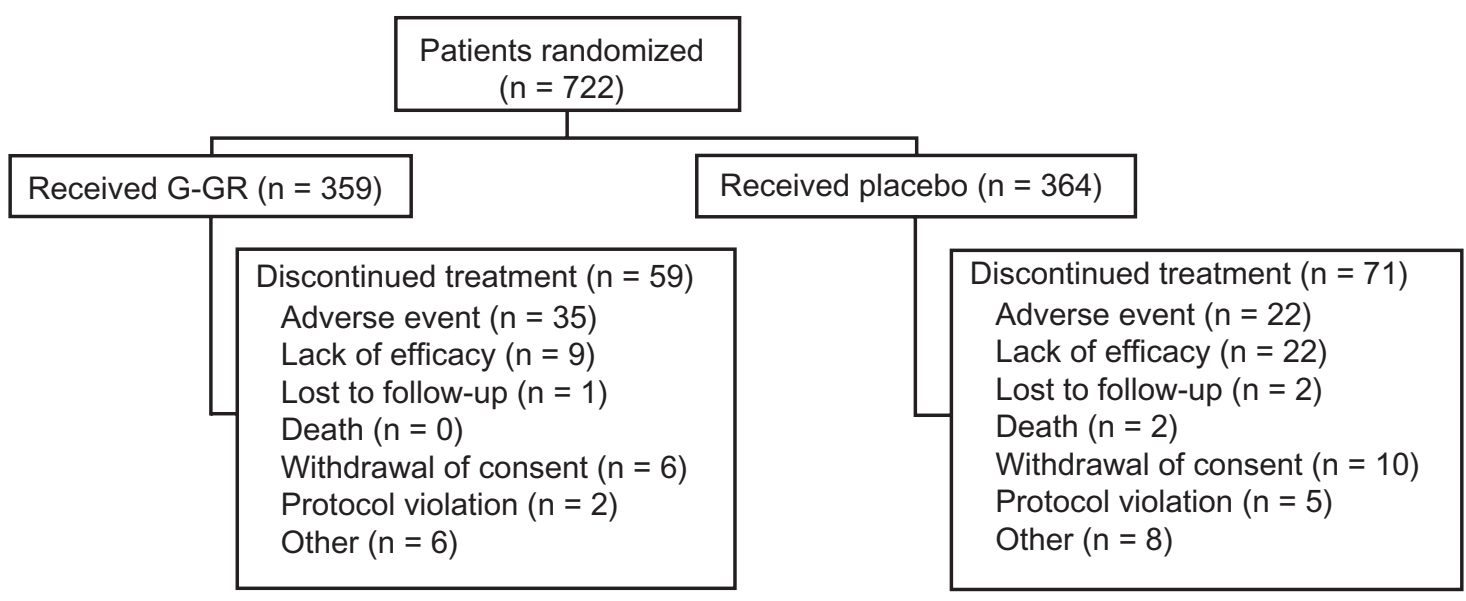

Figure 2 Patient disposition, safety population. Abbreviation: G-GR, once-daily gabapentin.
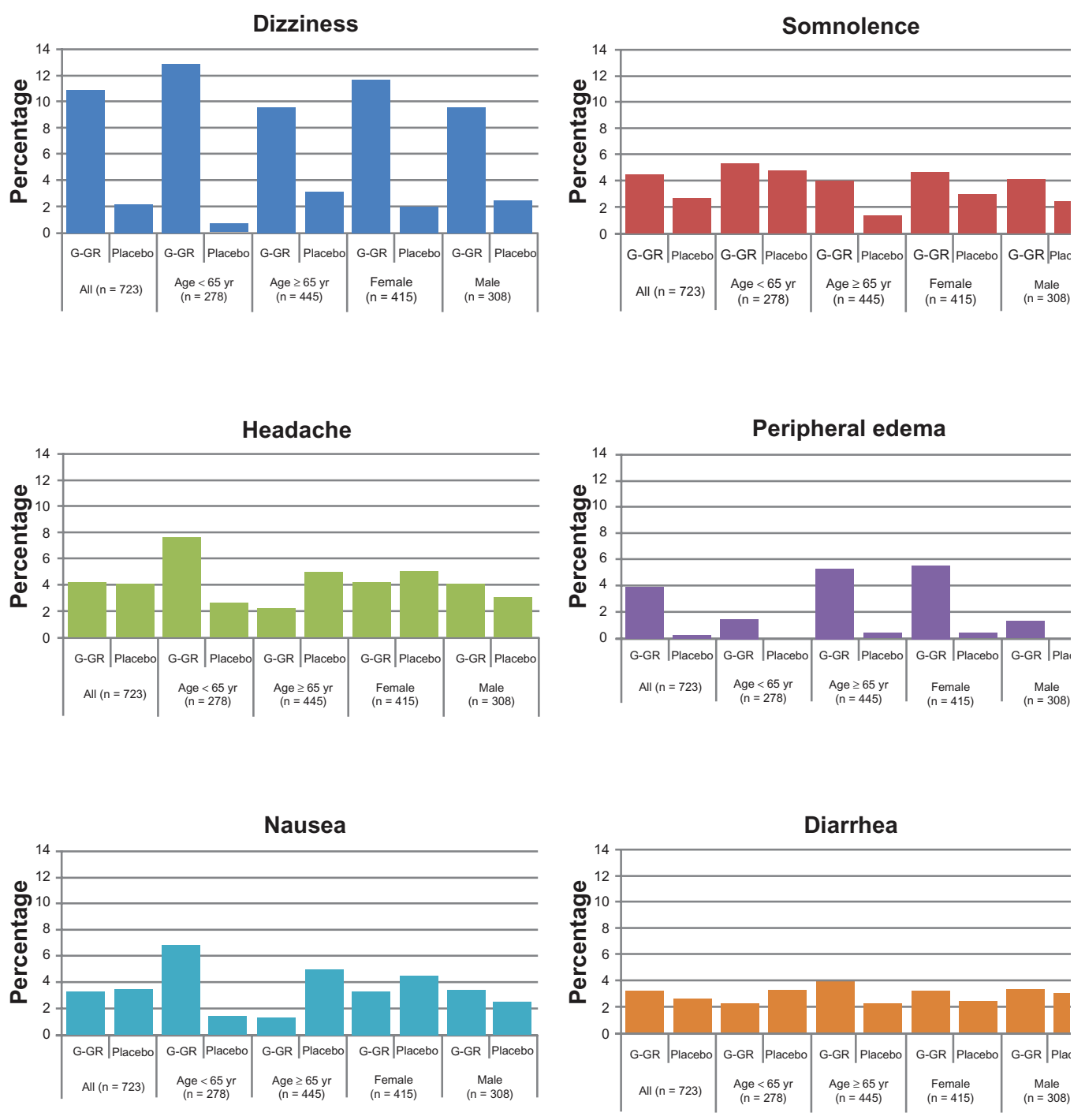

Figure 3 Subgroup analyses, adverse events (with $>3 \%$ incidence in patients in G-GR cohort). Abbreviation: G-GR, once-daily gabapentin. 
And patients $\geq 65$ years of age reported more incidences of peripheral edema ( $\geq 65$ years: G-GR, 5.3\%; placebo, $0.5 \%$; <65 years: G-GR, $1.5 \%$; placebo, $0 \%$ ). Peripheral edema was also more frequently reported in females who received G-GR (females: G-GR, 5.6\%; placebo, $0.5 \%$ vs males: G-GR, 1.4\%; placebo, $0 \%$ ).

Adverse events related to vital sign abnormalities were reported more frequently for patients in the G-GR group compared with the placebo group (G-GR, 15.0\% vs placebo, 6.6\%). Of these, dizziness and weight gain were the most common related AEs. There were no meaningful clinical differences between groups for the mean baseline values and mean changes from baseline for vital signs, weight, or measured laboratory parameters (blood panel, serum lipid profile, liver function tests, renal panel).

\section{Discussion}

This analysis of the pooled safety data from two phase 3 studies provides further support for the safety and tolerability of the once-daily G-GR formulation of gabapentin. The most common treatment-emergent AEs were the same as those previously identified in studies of gabapentin TID. The current analysis, as well as data from each of the component studies, ${ }^{7,8}$ demonstrate that the incidences of dizziness and somnolence in patients treated with G-GR (1800 mg/day) were lower than reported in previous studies with gabapentin TID. ${ }^{9}{ }^{10}$ Placebo-controlled trials of gabapentin TID in patients with PHN that used 1800 or $2400 \mathrm{mg} /$ day $^{9}$ or up to $3600 \mathrm{mg} /$ day $^{10}$ reported rates of treatmentassociated dizziness from $24 \%-33 \%$, and rates of treatmentassociated somnolence of $17 \%-27 \%{ }^{9}{ }^{9}, 10$ However, because the G-GR studies used in this integrated analysis did not directly compare G-GR with gabapentin TID, we cannot exclude the possibility that other differences between the studies contributed to differences in the AE profiles. Almost all patients were able to achieve the $1800 \mathrm{mg}$ dose in 2 weeks. This is in contrast to data obtained from a retrospective database analysis that showed that only $14 \%$ of PHN patients prescribed gabapentin TID were able to achieve an $1800 \mathrm{mg}$ dose and that it took on average 10 weeks to achieve this dose. ${ }^{11}$

It is notable that the incidences of dizziness and somnolence reported in a study with an extended-release formulation of a gabapentin prodrug (gabapentin encarbil) appeared to be unrelated to either the peak concentration or the absolute level of gabapentin. ${ }^{12}$ It is possible that treatment-associated AEs with G-GR are mitigated in part by the more gradual elevation in serum levels of gabapentin than the immediate-release formulation. In clinical trials with gabapentin TID, dizziness and somnolence are most frequently observed during the initial titration period, ${ }^{13}$ and plasma concentrations of that formulation also demonstrate more marked fluctuations early in the course of treatment. ${ }^{14}$ Alternatively, the apparent reduction in AEs with G-GR could be in part a result of gabapentin released from G-GR reaching peak concentrations during the period when most patients are asleep ${ }^{15}$ and therefore less likely to notice them. The tolerability of G-GR did not appear to be affected by patient age. Given that PHN is a disease for which the risk and duration of PHN increases with age, ${ }^{1}$ medications such as gabapentin, with good tolerability and a low propensity for drug-drug interactions, ${ }^{16}$ are particularly well suited. In addition, in the one study from which data were available, the rate of $\mathrm{AEs}$ in $\mathrm{G}-\mathrm{GR}$-treated patients with $\mathrm{CrCl}$ from $50 \mathrm{~mL} /$ minute to $<80 \mathrm{~mL} /$ minute was only slightly higher compared with those having $\mathrm{CrCl} \geq 80 \mathrm{~mL} /$ minute, suggesting that mild or moderate renal impairment $(\mathrm{CrCl} \geq 50 \mathrm{~mL} /$ minute) did not markedly affect tolerability of G-GR.

One limitation of the current integrated analysis is that it only examined tolerability and safety data for a 10 -week treatment period. But given the extensive clinical history of gabapentin TID for the treatment of neuropathic pain and the established safety of the gastroretentive technology, ${ }^{17}$ it is reasonable to expect that the safety and tolerability of G-GR would be maintained for longer treatment periods. Another limitation of this analysis is that patients who had not previously responded to gabapentin at daily doses $>1200 \mathrm{mg}$ or who were intolerant to gabapentin were excluded. Although this exclusion criterion may have enriched the study population with patients likely to be tolerant of gabapentin, its intent was to treat patients ethically. It would be unfair to require a patient to enroll in a 11-week study investigating a once-daily formulation of a drug they had previously been unable to tolerate or from which they had obtained no pain relief. This same approach was used in previous studies of gabapentin TID and pregabalin in patients with $\mathrm{PHN}^{9,18,19}$ and as such the patient populations in G-GR clinical trials and previous studies of gabapentin TID and pregabalin are comparable.

\section{Conclusion}

In conclusion, the results of this analysis, together with the previous demonstration of efficacy in this patient population, ${ }^{8}$ suggest that G-GR has the potential to provide an efficacious, well-tolerated, and convenient treatment option in the treatment of PHN. 


\section{Acknowledgments}

Editorial support was provided by Ed Parr, PhD, CMPP, of Envision Scientific Solutions, Southport, CT, and funded by Abbott. Medical writing support was provided by Stephanie Kareht, PhD, at Depomed. The authors thank Eric Sondag, $\mathrm{PhD}$, formerly of Abbott, and Geertrui Vanhove, MD, PhD, from Depomed for their suggestions and advice during development of the manuscript, and Stephanie Kareht, $\mathrm{PhD}$ for assistance with the production of figures.

\section{Disclosure}

These analyses were sponsored by Depomed. Gordon Irving has previously received an honorarium from Depomed for participation on an advisory board. Michael Sweeney is an employee of Depomed.

\section{References}

1. Dworkin RH, Portenoy RK. Pain and its persistence in herpes zoster. Pain. 1996;67:241-251.

2. Oxman MN, Levin MJ, Johnson GR, et al. A vaccine to prevent herpes zoster and postherpetic neuralgia in older adults. New Engl J Med. 2005;352:2271-2284.

3. Johnson RW, Wasner G, Saddier P, Baron R. Postherpetic neuralgia: epidemiology, pathophysiology and management. Expert Rev Neurother. 2007;7:1581-1595.

4. Pfizer. Neurontin [package insert]. New York: Pfizer; 2010.

5. Stewart BH, Kugler AR, Thompson PR, Bockbrader HN. A saturable transport mechanism in the intestinal absorption of gabapentin is the underlying cause of the lack of proportionality between increasing dose and drug levels in plasma. Pharm Res. 1993;10:276-281.

6. [No authors listed]. Gabapentin extended-release - Depomed: gabapentin ER, gabapentin gastric retention, gabapentin GR. Drugs $R$ D. 2007;8:317-320.

7. Wallace MS, Irving G, Cowles VE. Gabapentin extended-release tablets for the treatment of patients with postherpetic neuralgia: a randomized, double-blind, placebo-controlled, multicentre study. Clin Drug Investig. 2010;30:765-776.
8. Sang CN, Sathyanarayana R, Sweeney M. Once-daily gabapentin (G-GR) reduces intensity of pain associated with post herpetic neuralgia. Clin J Pain. 2012; In press.

9. Rice ASC, Maton S, Group PNS. Gabapentin in postherpetic neuralgia: a randomised, double blind, placebo controlled study. Pain. 2001;94:215-224.

10. Rowbotham M, Harden N, Stacey B, Bernstein P, Magnus-Miller L. Gabapentin for the treatment of postherpetic neuralgia: a randomized controlled trial. JAMA. 1998;280:1837-1842.

11. Johnson P, Becker L, Halpern R, Sweeney T. Dosing patterns, therapy outcomes and health care costs among patients with postherpetic neuralgia (PHN) treated with gabapentin or pregabalin. Pharmacoeconomics. [Submitted.]

12. Cundy KC, Sastry S, Luo W, Zou J, Moors TL, Canafax DM. Clinical pharmacokinetics of XP13512, a novel transported prodrug of gabapentin. J Clin Pharmacol. 2008;48:1378-1388.

13. Backonja M, Glanzman RL. Gabapentin dosing for neuropathic pain: evidence from randomized, placebo-controlled clinical trials. Clin Ther. 2003;25:81-104.

14. Gordi T, Hou E, Kasichayanula S, Berner B. Pharmacokinetics of gabapentin after a single day and at steady state following the administration of gastric-retentive- extended-release and immediate-release tablets: a randomized, open-label, multiple-dose, three-way crossover, exploratory study in healthy subjects. Clin Ther. 2008;30:909-916.

15. Chen C, Cowles VE, Hou E. Pharmacokinetics of gabapentin in a novel gastric-retentive extended-release formulation: comparison with an immediate-release formulation and effect of dose escalation and food. J Clin Pharmacol. 2011;51:346-358.

16. Johnson RW, Wasner G, Saddier P, Baron R. Herpes zoster and postherpetic neuralgia: optimizing management in the elderly patient. Drugs Aging. 2008;25:991-1006.

17. Berner B, Cowles VE. Case studies in swelling polymeric gastric retentive tablets. Expert Opin Drug Deliv. 2006;3:541-548.

18. Dworkin RH, Corbin AE, Young JP Jr, et al. Pregabalin for the treatment of postherpetic neuralgia: a randomized, placebo-controlled trial. Neurology. 2003;60:1274-1283.

19. van Seventer R, Feister HA, Young JP Jr, Stoker M, Versavel M, Rigaudy L. Efficacy and tolerability of twice-daily pregabalin for treating pain and related sleep interference in postherpetic neuralgia: a 13-week, randomized trial. Curr Med Res Opin. 2006;22:375-384.
Journal of Pain Research

\section{Publish your work in this journal}

The Journal of Pain Research is an international, peer-reviewed, open access, online journal that welcomes laboratory and clinical findings in the fields of pain research and the prevention and management of pain. Original research, reviews, symposium reports, hypothesis formation and commentaries are all considered for publication.

\section{Dovepress}

The manuscript management system is completely online and includes a very quick and fair peer-review system, which is all easy to use. Visit http://www.dovepress.com/testimonials.php to read real quotes from published authors. 